Supporting Information for

\title{
Ultrathin and Wavy PdB Alloy Nanowires with Controlled Surface Defects for Enhanced Ethanol Oxidation Electrocatalysis
}

Yaru Wang, ${ }^{1}$ Hao Lv, ${ }^{2}$ Lizhi Sun, ${ }^{1}$ Xuwen Guo, ${ }^{1}$ Dongdong Xu, ${ }^{1, *}$ and Ben Liu ${ }^{1,2, *}$

${ }^{1}$ Jiangsu Key Laboratory of New Power Batteries, Jiangsu Collaborative Innovation Center of Biomedical Functional Materials, School of Chemistry and Materials Science, Nanjing Normal University, Nanjing 210023, China

${ }^{2}$ College of Chemistry, Sichuan University, Chengdu 610064, China

*Emails: ddxu@njnu.edu.cn; ben.liu@njnu.edu.cn 


\section{Chemicals and Materials}

Palladium(II) chloride $\left(\mathrm{PdCl}_{2}, 99.9\right.$ wt. \%), ammonium fluoride $\left(\mathrm{NH}_{4} \mathrm{~F}\right)$, boric acid $\left(\mathrm{H}_{3} \mathrm{BO}_{3}\right)$, borane dimethylamine complex (DMAB), cetyltrimethylammonium chloride $\left(\mathrm{C}_{16} \mathrm{TAC}\right)$, 1-hexade cylpyridinium $\left(\mathrm{C}_{16}\right.$-py), dioctadecyldimethylammonium chloride (DODAC), sodium borohydride $\left(\mathrm{NaBH}_{4}\right)$, ascorbic acid (AA), and acetic acid were obtained from Alfa Aesar. Nafion solution, commercial palladium nanoparticles (Pd NPs) was obtained from Sigma-Aldrich. Hydrochloric acid $(\mathrm{HCl})$, ammonia solution $\left(\mathrm{NH}_{3} \cdot \mathrm{H}_{2} \mathrm{O}\right)$ and sodium hydroxide $(\mathrm{NaOH})$ were purchased from Sinopharm Chemical Reagent Co. Ltd. (Shanghai). Behenyl trimethyl ammonium chloride $\left(\mathrm{C}_{22}\right.$ TAC) was synthesized according to our previously reported work (Chem. Sci. 2018, 9, 4451; J. Phys. Chem. Lett. 2019, 10, 663). To prepare $10 \mathrm{mM} \mathrm{H}_{2} \mathrm{PdCl}_{4}$ solution, $0.355 \mathrm{~g}$ of $\mathrm{PdCl}_{2}$ was first dissolved into $20 \mathrm{~mL}$ of 0.2 $\mathrm{M} \mathrm{HCl}$ solution, and then diluted with $180 \mathrm{~mL}$ of deionized $\mathrm{H}_{2} \mathrm{O}$. Deionized $\mathrm{H}_{2} \mathrm{O}$ with the resistivity of $18.25 \mathrm{~m} \Omega$ was used in all experiments.

\section{Synthesis of binary PdB alloy nanowires (NWs)}

Binary PdB NWs were synthesized by an aqueous route using $\mathrm{H}_{2} \mathrm{PdCl}_{4}$ as the metal precursor, $\mathrm{C}_{16} \mathrm{~N}-\mathrm{Py}$ as the surfactant template, DMAB as the B sources and the reduce agents. In a typical synthesis, $20 \mathrm{mg}$ of $\mathrm{C}_{16} \mathrm{~N}-\mathrm{Py}$ was totally dissolved in $5.0 \mathrm{~mL}$ of deionized $\mathrm{H}_{2} \mathrm{O}$ to obtain a homogeneous solution, followed by the addition of 0.5 $\mathrm{mL}$ of $0.337 \mathrm{M} \mathrm{NH}_{4} \mathrm{~F}$ solution, $0.5 \mathrm{~mL}$ of $0.101 \mathrm{M} \mathrm{H}_{3} \mathrm{BO}_{3}$ solution, and $0.4 \mathrm{~mL}$ of $10 \mathrm{mM} \mathrm{H}_{2} \mathrm{PdCl}_{4}$ solution. After incubated for $5 \mathrm{~min}, 0.20 \mathrm{~mL}$ of $\mathrm{NH}_{3} \bullet \mathrm{H}_{2} \mathrm{O}(10 \mathrm{wt}$. \%) was injected to adjust the $\mathrm{pH}$ of the solution. The color of the solution was changed from pink to colorless correspondingly. After that, the solution was heated to $50{ }^{\circ} \mathrm{C}$ and kept constant for $30 \mathrm{~min}$. Lastly, $0.50 \mathrm{~mL}$ of freshly prepared $0.10 \mathrm{M} \mathrm{DMAB}$ was injected to start the reduction and crystallization growth of PdB alloys. In this stage, the color of the solution was gradually evolved into dark brown. After kept at $50{ }^{\circ} \mathrm{C}$ for $120 \mathrm{~min}$, the product was collected by centrifuged and washed several times with ethanol/ $\mathrm{H}_{2} \mathrm{O}$. Besides, $\mathrm{pH}$, reaction temperatures and the species of the surfactants were also tuned to tailor the nanostructures of as-resulted PdB NWs under the similar procedures.

Monometallic Pd NWs were obtained using DODAC and $\mathrm{NaBH}_{4}$ as the surfactant templates and reducing agent (see Sci. China, Chem. 2020, 10.1007/s11426-020-9872-4 for more synthetic details).

\section{Electrochemical ethanol oxidation reaction (EOR) measurements}

Electrochemical EOR measurements were carried out using a three-electrode system at $25^{\circ} \mathrm{C}$, with a glass carbon electrode (GCE, $0.07065 \mathrm{~cm}^{2}$ ) connected to an $\mathrm{CHI} 660 \mathrm{E}$ electrochemical workstation, a carbon rod as the counter electrode, and a $\mathrm{Ag} / \mathrm{AgCl}$ electrode as the reference electrode. Before the electrochemical tests, assynthesized nanocatalysts were cleaned with ethanol/ $\mathrm{H}_{2} \mathrm{O}$ for seven times to remove the surfactants totally (Chem. Sci. 2019, 10, 1986; ACS Cent. Sci. 2018, 4, 1412). Then, obtained nanocatalysts were freeze-dried at $-60{ }^{\circ} \mathrm{C}$. To prepare a nanocatalyst ink, $0.50 \mathrm{mg}$ of the nanocatalysts and $4.0 \mathrm{mg}$ of Vulcan XC-72 carbon were added to 0.80 
$\mathrm{mL}$ of ethanol and $0.20 \mathrm{~mL}$ of $\mathrm{H}_{2} \mathrm{O}$, and further mixed by sonicating for $30 \mathrm{~min}$. Subsequently, $50 \mu \mathrm{L}$ of Nafion solution (5 wt. \% in alcohol and $\mathrm{H}_{2} \mathrm{O}$ ) was added and sonicated for another $30 \mathrm{~min}$. Then, $6.0 \mu \mathrm{L}$ of aboveprepared ink solution ( $3.0 \mu \mathrm{g}$ of the nanocatalyst) was dropped on the GCE electrode and dried at $40{ }^{\circ} \mathrm{C}$ before the test. Cyclic voltammograms (CVs) were then scanned until the stabilized curves were obtained for further removal of the surfactant in $\mathrm{N}_{2}$-saturated $1 \mathrm{M} \mathrm{KOH}$. CVs were used to evaluate the electrochemical surface areas (ECSAs) of the nanocatalysts with the scan rate of $50 \mathrm{mV} \mathrm{s}^{-1} . \mathrm{CV}$ curves of the nanocatalysts were measured in the potential range of $-0.9-0.2 \mathrm{~V}$ in $\mathrm{N}_{2}$-saturated $1.0 \mathrm{M} \mathrm{KOH}$ and $1.0 \mathrm{M}$ ethanol solutions to evaluate the activities of the electrocatalysts. The kinetics of the nanocatalysts were collected with different scan rates and different ethanol concentrations. And, the samples after the stability tests were also collected from the GCE electrode for evaluating the structural stability by TEM.

The ECSA of the nanocatalyst was calculated by the following equation:

$$
\mathrm{ECSA}=\frac{\mathrm{Q}_{\mathrm{PdO}}}{0.405 \mathrm{mC} \mathrm{cm}^{-2} \times m_{P d}}
$$

where $\mathrm{Q}_{\mathrm{PdO}}$ is the charge by integrated the reduction peak area of $\mathrm{PdO}$ to $\mathrm{Pd}, 0.405 \mathrm{mC} \mathrm{cm}^{-2}$ is the charge for the reduction of $\mathrm{PdO}$, and $\mathrm{m}_{\mathrm{Pd}}$ is the mass of $\mathrm{Pd}$ on the electrode.

The activation energy $\Delta E_{\mathrm{a}}$ values of catalysts were calculated based on the Arrhenius equation as follows:

$$
\mathrm{I}=\mathrm{A} e^{-\frac{\Delta E_{a}}{R T}}
$$

where $\mathrm{I}$ is the current at a specific potential, $\mathrm{R}$ is the gas content $\left(8.315 \mathrm{~J} \mathrm{~mol}^{-1} \mathrm{~K}^{-1}\right)$, T is the test temperature in $\mathrm{K}$ and $\Delta E_{\mathrm{a}}$ is the apparent activation energy at a specific potential.

\section{Characterizations}

Transmission electron microscopy (TEM) and high-angle annular dark-field scanning TEM (HAADF-STEM) were performed on the JEM-F200, JEOL at an accelerating voltage of $200 \mathrm{kV}$, which are equipped with STEM and EDS detectors for elemental mapping analysis. TEM and STEM samples were prepared by casting a suspension of the samples (in ethanol and/or $\mathrm{H}_{2} \mathrm{O}$ ) on a carbon coated copper grid (300 mesh). X-ray diffraction (XRD) patterns were collected on the powder samples using a D/max $2500 \mathrm{VL} / \mathrm{PC}$ diffractometer (Japan) equipped with graphite-monochromatized $\mathrm{Cu} \mathrm{K} \alpha$ radiation. X-ray photoelectron spectra (XPS) were performed on a scanning X-ray microprobe (Thermo ESCALAB 250Xi) that uses Al Ka radiation. The binding energy of the C 1s peak $(284.8 \mathrm{eV})$ was employed as a standard to calibrate the binding energies of other elements. Inductively coupled plasma mass spectrometry (ICP-MS) was recorded on a NexION 350D. 


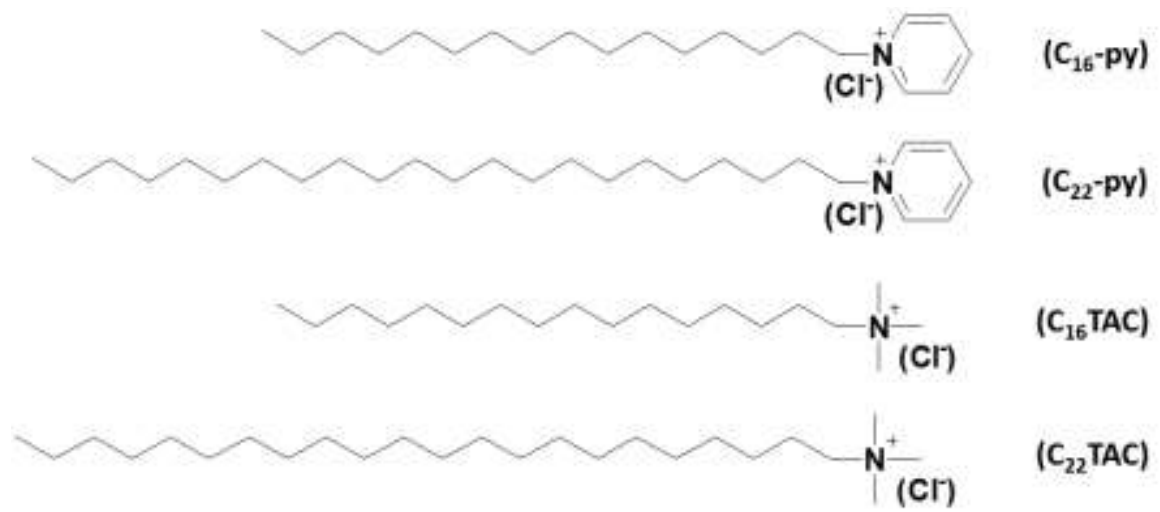

Figure S1. Chemical structures and corresponding abbreviations of functional surfactants used in this work $\left(\mathrm{C}_{16^{-}}\right.$ py, $\mathrm{C}_{22}$-py, $\mathrm{C}_{16} \mathrm{TAC}$, and $\left.\mathrm{C}_{22} \mathrm{TAC}\right)$.
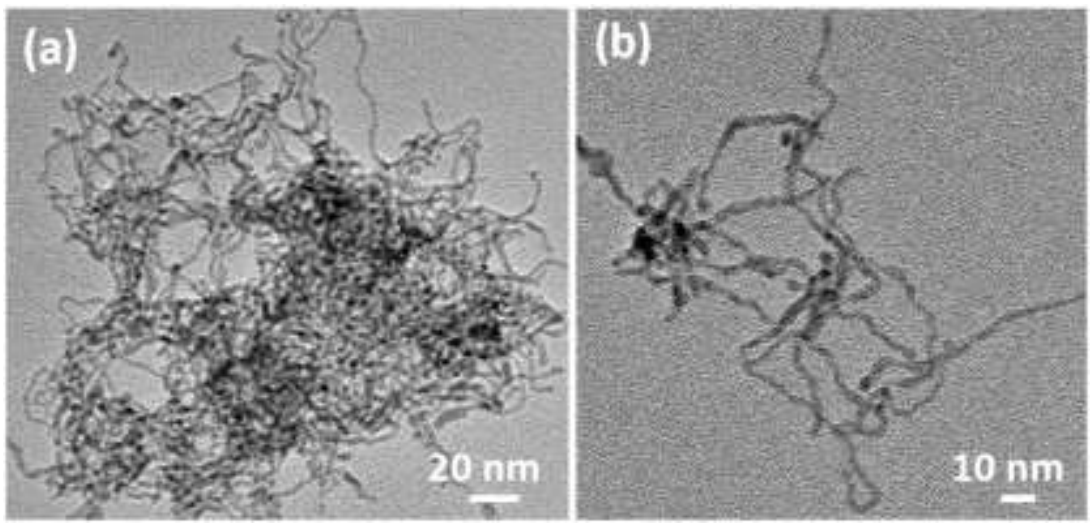

Figure S2. TEM images of monometallic Pd NWs with different magnifications.

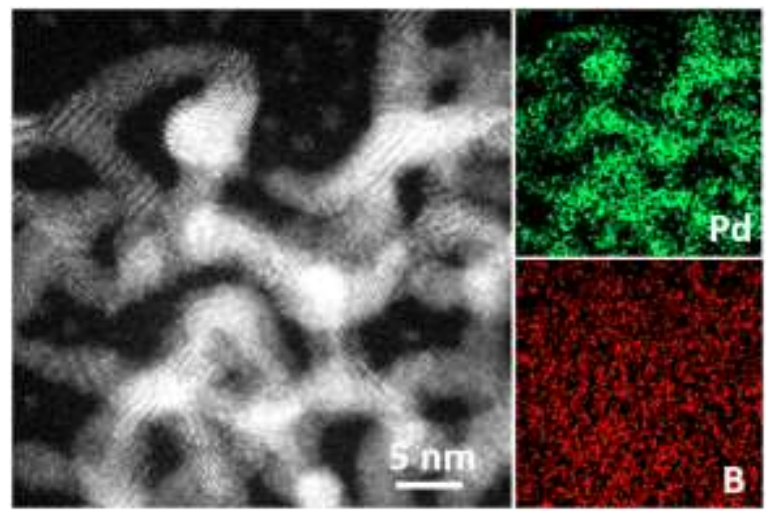

Figure S3. STEM elemental map images of binary PdB alloy NWs. 

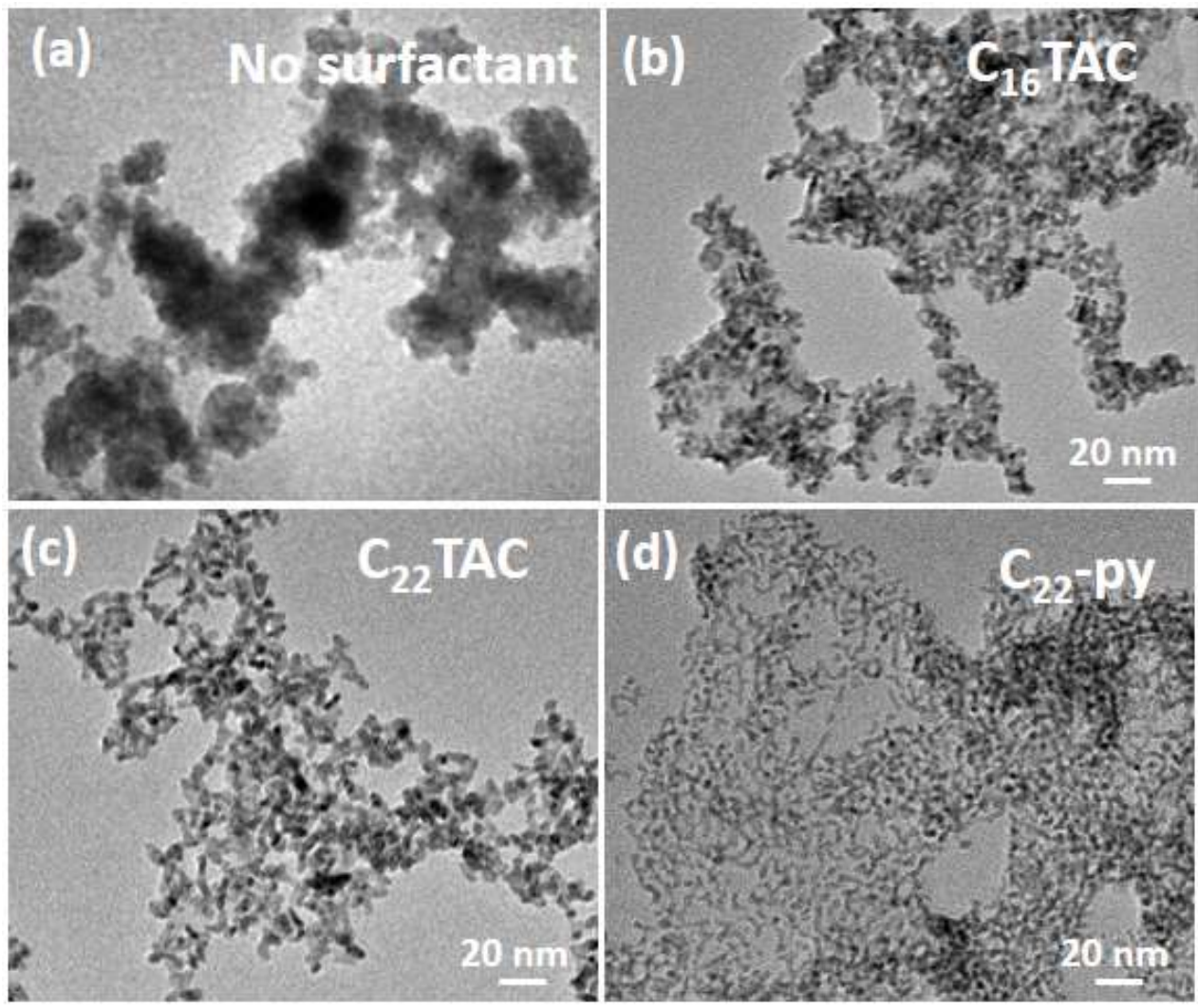

Figure S4. TEM images of PdB alloys synthesized under different surfactants of (a) no surfactant, (b) $\mathrm{C}_{16}$ TAC, (c) $\mathrm{C}_{22}$ TAC and (d) $\mathrm{C}_{22}$-py. The types of functional surfactants are strongly relative to assembled mesophases, and thus affect their nanostructures.
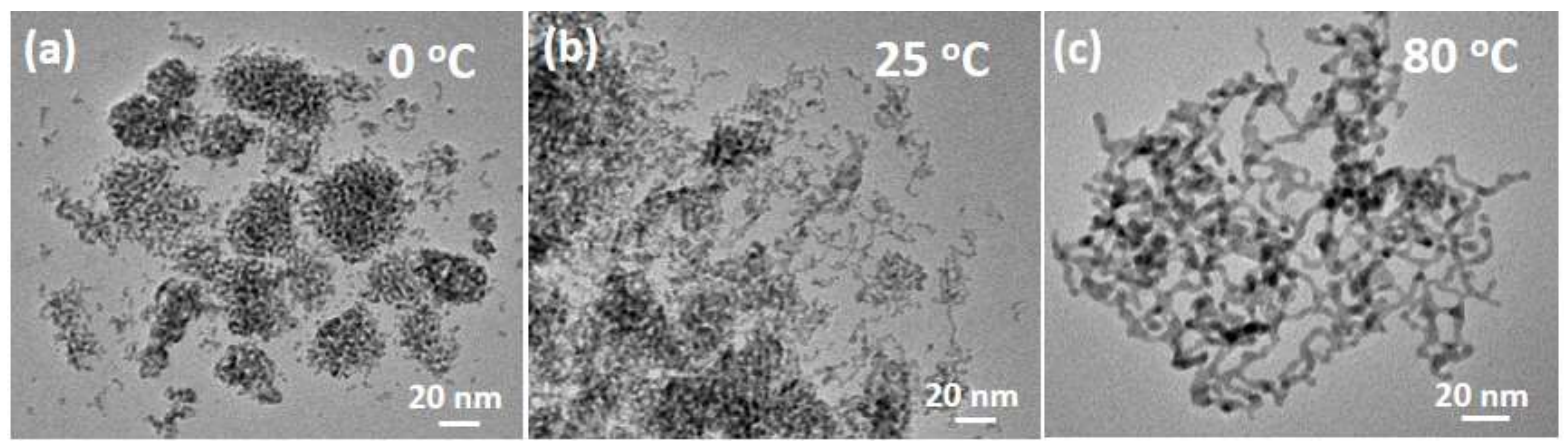

Figure S5. TEM images of $\mathrm{PdB}$ alloys synthesized under different reaction temperatures of (a) $0{ }^{\circ} \mathrm{C}$, (b) $25{ }^{\circ} \mathrm{C}$, and (c) $80{ }^{\circ} \mathrm{C}$. Synthetic temperatures are strongly relative to the reaction and nucleation rates, and thus affect their nanostructures. 

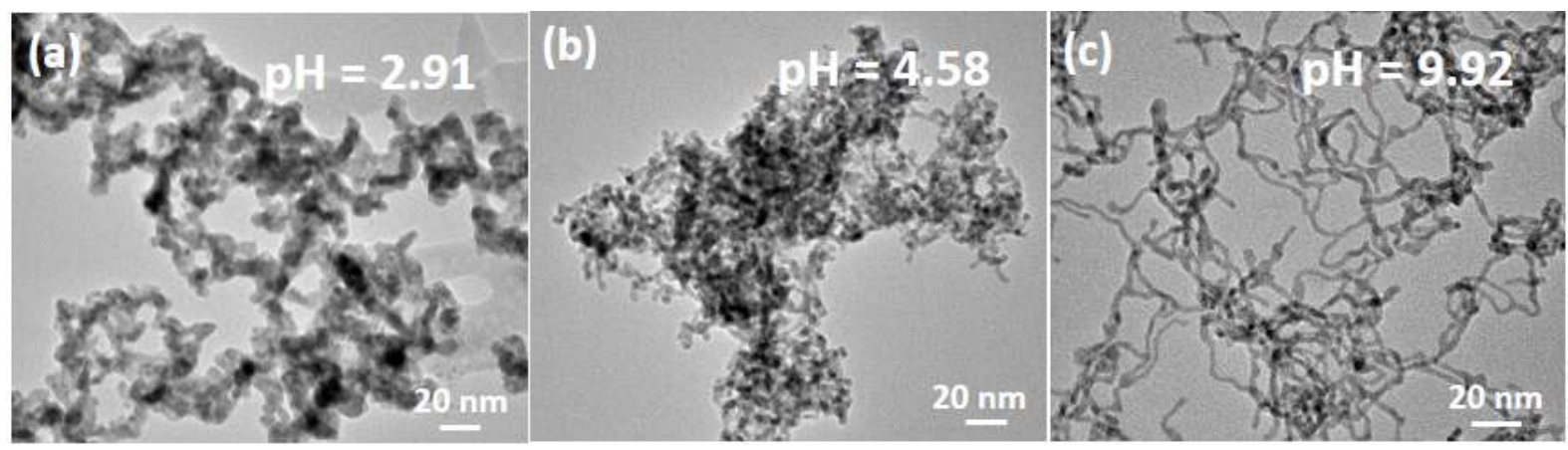

Figure S6. TEM images of PdB alloys synthesized under different pH values of (a) 2.91, (b) 4.58, and (c) 9.92. Synthetic temperatures are strongly relative to the assembled mesophases and reduction rates, and thus affect their nanostructures.

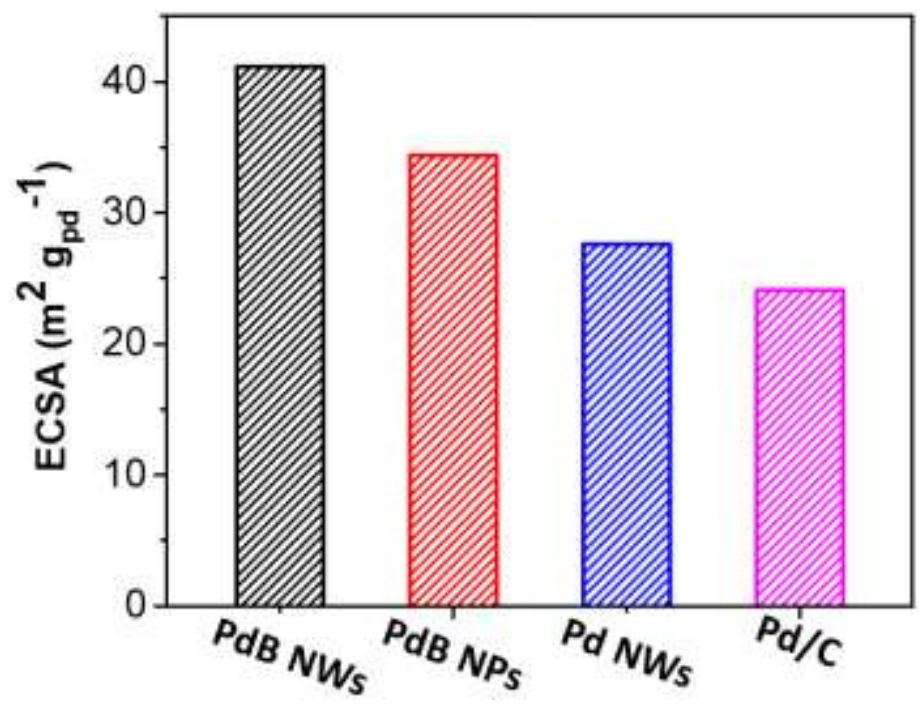

Figure S7. ESCA values of PdB NWs, PdB NPs, Pd NWs, and Pd/C calculated from CVs in Figure 5a. 

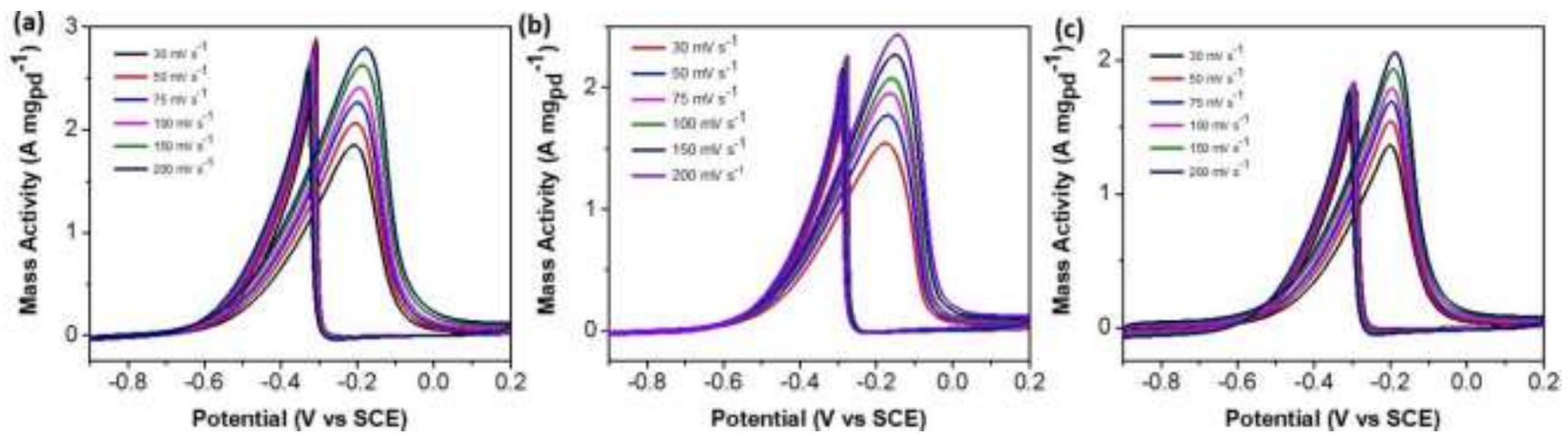

Figure S8. CV curves of (a) PdB NPs, (b) Pd NWs, and (c) Pd/C collected under different scan rates from 30 to $200 \mathrm{mV} \mathrm{s}^{-1}$.
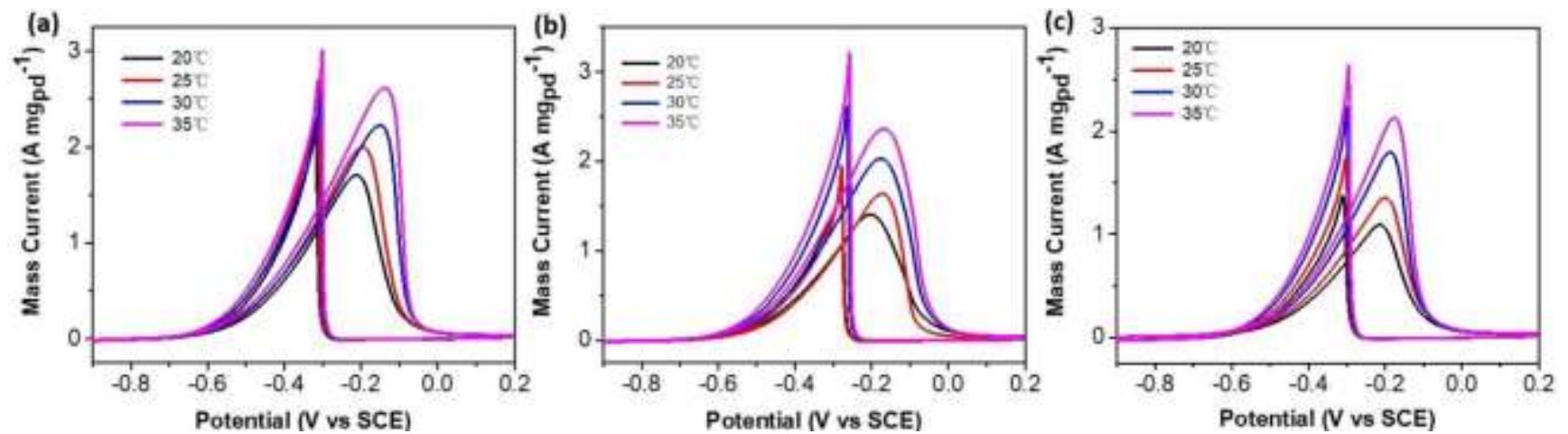

Figure S9. CV curves of (a) PdB NPs, (b) Pd NWs, and (c) Pd/C collected under different test temperatures from 20 to $35^{\circ} \mathrm{C}$.

$$
\begin{aligned}
& \mathrm{Pd}+\mathrm{CH}_{3} \mathrm{CH}_{2} \mathrm{OH}+3 \mathrm{OH}^{-} \rightarrow \mathrm{Pd}-\left(\mathrm{CH}_{3} \mathrm{CO}\right)_{\text {ads }}+3 \mathrm{H}_{2} \mathrm{O}+3 \mathrm{e}^{-} \\
& \mathrm{Pd}+\mathrm{OH}^{-} \rightarrow \mathrm{Pd}-\mathrm{OH}_{\text {ads }}+e^{-} \\
& \mathrm{Pd}-\left(\mathrm{CH}_{3} \mathrm{CO}\right)_{a d s}+\mathrm{Pd}-\mathrm{OH}_{a d s} \rightarrow \mathrm{Pd}-\mathrm{CH}_{3} \mathrm{COOH}+\mathrm{Pd} \\
& \mathrm{Pd}-\mathrm{CH}_{3} \mathrm{COOH}+\mathrm{OH}^{-} \rightarrow \mathrm{Pd}+\mathrm{CH}_{3} \mathrm{COO}^{-}+\mathrm{H}_{2} \mathrm{O}
\end{aligned}
$$

Figure S10. Electrocatalytic EOR processes on Pd catalyst.

Note Figure S10: EOR electrocatalysis proceeds on Pd according to the above processes, in which the removal and/or further oxidation of $\mathrm{CO}$-based poisoning intermediates (for example $\mathrm{CH}_{3} \mathrm{CO}_{\mathrm{ads}}, \mathrm{CH}_{3} \mathrm{COO}_{\mathrm{ads}}, \mathrm{CO}_{\mathrm{ads}}$, and others) is the rate-determining step (eq. 3). 


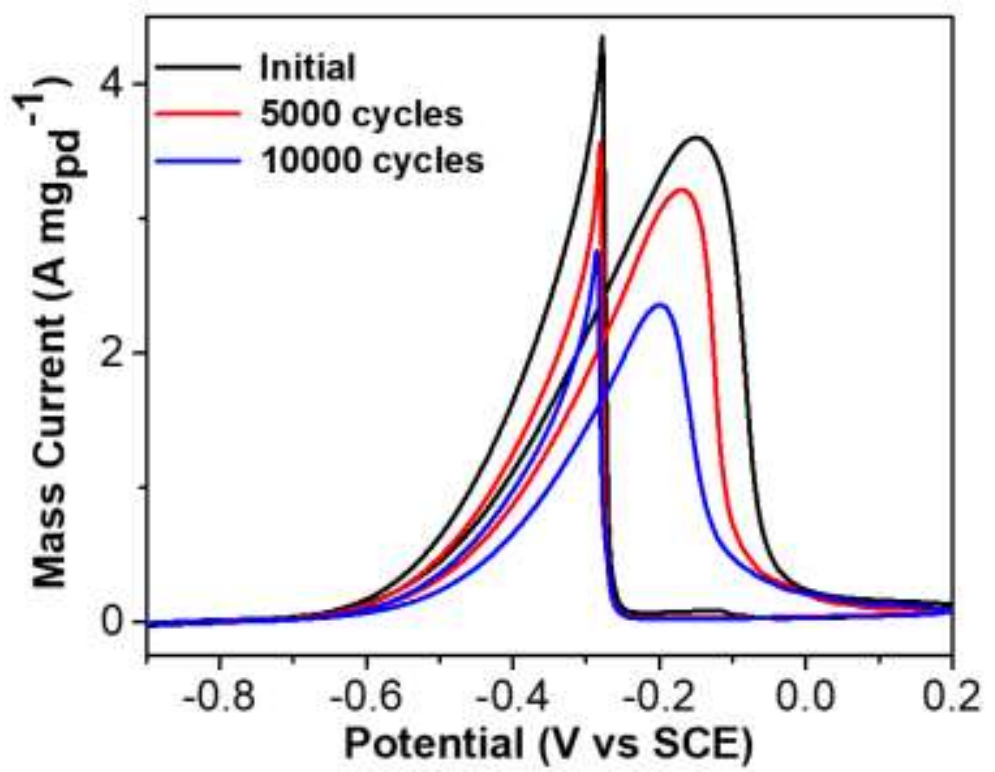

Figure S11. Electrocatalytic EOR stability of ultrathin PdB alloy NWs for continuously scanning CVs for 10000 cycles.

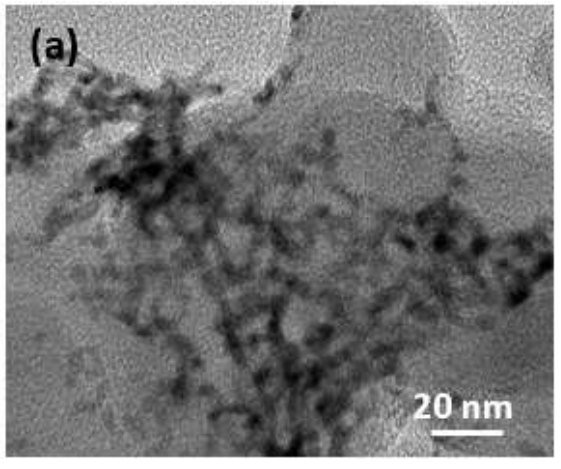

(b)

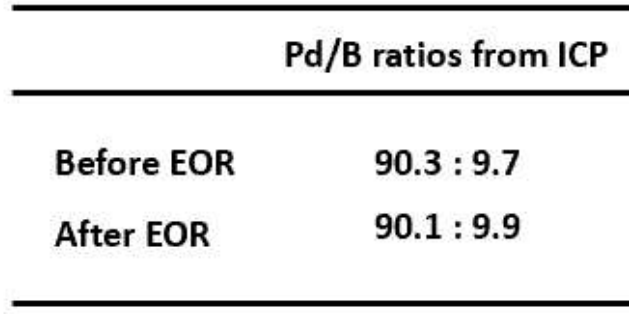

Figure S12. (a) TEM image of bimetallic PdB alloy NWs after the stability test. (b) Compositional ratios of Pd/B in bimetallic PdB alloy NWs before and after stability tests collected from ICP. 

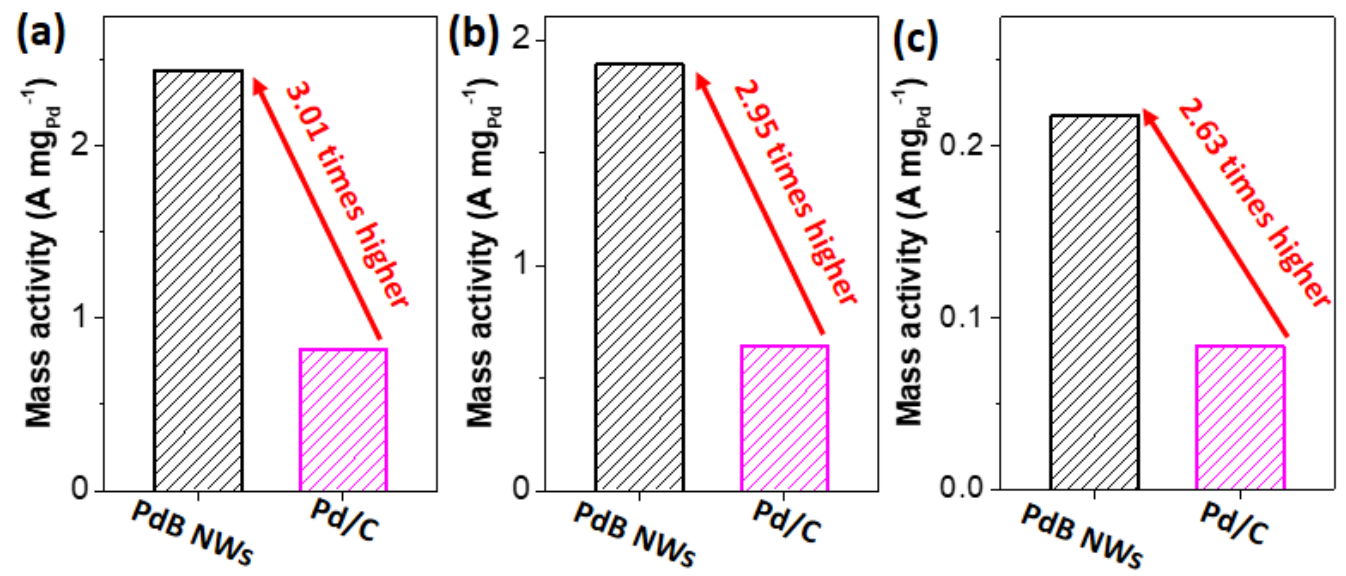

Figure S13. Summarized mass activities of PdB NWs and Pd/C toward electrocatalytic oxidation of (a) methanol, (b) glycerol, and (c) glucose. 